\title{
Biodegradation and tissue integration of various polyethylene glycol matrices: a comparative study in rabbits
}

Thoma, Daniel S ; Weber, Franz E ; Bienz, Stefan P ; Ge, Yanjun ; Hämmerle, Christoph H F ; Jung, Ronald E

\begin{abstract}
OBJECTIVES: To test whether or not chemical and/or physical modifications of polyethylene glycol (PEG) hydrogels influence degradation time, matrix/membrane stability, and integration into surrounding hard and soft tissues. MATERIAL AND METHODS: In 28 rabbits, six treatment modalities were randomly applied to six sites on the rabbit skull: a dense network PEG hydrogel (PEG HD), a medium-dense network PEG hydrogel (PEG MD), a medium-dense network PEG hydrogel modified with an RGD sequence (PEG MD/RGD), a mediumdense network PEG hydrogel modified with RGD with reduced carboxymethyl cellulose (PEG MD/RGD_LV), a loose network PEG hydrogel modified with RGD (PEG LD/RGD), and a collagen membrane (BG). Descriptive histology and histomorphometry were performed at 1, 2, 4, and 6 weeks. RESULTS: PEG HD revealed the highest percentage of residual matrix at all time points starting with $47.2 \%$ (95\% CI: 32.8-63.8\%) at 1 week and ending with $23.4 \%$ (95\% CI: 10.3-49.8\%) at 6 weeks. The hydrogel with the loosest network (PEG LD/RGD) was stable the first 2 weeks and then degraded continuously with a final area of $8.3 \%$ (95\% CI: 3.2-21.2\%). PEG HD was the most stable and densely stained membrane, whereas PEG MD and PEG LD matrices integrated faster, but started to degrade to a higher degree between 2 and 4 weeks. PEG MD degradation was dependent on the addition of RGD and the amount of CMC. CONCLUSIONS: Chemical and/or physical modifications of PEG hydrogels influenced matrix stability. PEG MD/RGD demonstrated an optimal balance between degradation time and integration into the surrounding soft and hard tissues.
\end{abstract}

DOI: https://doi.org/10.1111/clr.13004

Posted at the Zurich Open Repository and Archive, University of Zurich

ZORA URL: https://doi.org/10.5167/uzh-136333

Journal Article

Accepted Version

Originally published at:

Thoma, Daniel S; Weber, Franz E; Bienz, Stefan P; Ge, Yanjun; Hämmerle, Christoph H F; Jung, Ronald E (2017). Biodegradation and tissue integration of various polyethylene glycol matrices: a comparative study in rabbits. Clinical Oral Implants Research, 28(11):e244-e251.

DOI: https://doi.org/10.1111/clr.13004 


\section{Biodegradation and tissue integration of various polyethylene glycol matrices: a comparative study in rabbits}

Daniel S. Thoma ${ }^{1}$, Franz E. Weber, Stefan P. Bienz ${ }^{1}$, Yenjun $\mathrm{Ge}^{3}$, Christoph H. F. Hämmerle ${ }^{1}$, Ronald E. Jung ${ }^{1}$

Key words: guided tissue regeneration, bone, bone regeneration, polyethylene glycols, bone substitute, animal experiments (all MeSH terms)

Running title: Degradation of polyethylene glycol hydrogels

Number of figures: 3

Number of tables: 1

Address for correspondence: $\quad$ PD Dr. med dent. Daniel S. Thoma

Clinic of Fixed and Removable Prosthodontics and

Dental Material Science

Center of Dental Medicine, University of Zurich

Plattenstrasse 11

$\mathrm{CH}-8032$ Zurich, Switzerland

Phone: +41446343260

Fax: +41446344305

e-mail: daniel.thoma@zzm.uzh.ch

${ }^{1}$ Clinic for Fixed and Removable Prosthodontics and Dental Material Science, University of Zurich, Zurich, Switzerland

${ }^{2}$ Center of Dental Medicine, Oral Biotechnology \& Bioengineering University of Zurich, Zurich, Switzerland

${ }^{3}$ Former ITI scholar, Clinic for Fixed and Removable Prosthodontics and Dental Material Science, University of Zurich, Zurich, Switzerland 


\section{Abstract}

Objectives: to test whether or not chemical and/or physical modifications of polyethylene glycol (PEG) hydrogels influence degradation time, matrix/membrane stability and integration into surrounding hard and soft tissues.

Materials and methods: In 28 rabbits, six treatment modalities were randomly applied to 6 sites on the rabbit skull: a dense network PEG hydrogel (PEG HD), a medium-dense network PEG hydrogel (PEG MD), a medium-dense network PEG hydrogel modified with an RGD sequence (PEG MD/RGD), a medium-dense network PEG hydrogel modified with RGD with reduced carboxymethyl cellulose (PEG MD/RGD_LV), a loose network PEG hydrogel modified with RGD (PEG LD/RGD) and a collagen membrane (BG). Descriptive histology and histomorphometry were performed at 1, 2, 4 and 6 weeks.

Results: PEG HD revealed the highest percentage of residual matrix at all time-points starting with $47.2 \%$ (95\% CI: $32.8 \%-63.8 \%)$ at 1 week and ending with $23.4 \%$ (95\% CI: $10.3 \%$ $49.8 \%$ ) at 6 weeks. The hydrogel with the loosest network (PEG LD/RGD) was stable the first two weeks and then degraded continuously with a final area of $8.3 \%$ (95\% CI: $3.2 \%-21.2 \%$ ). PEG HD was the most stable and densely stained membrane, whereas PEG MD and PEG LD matrices integrated faster, but started to degrade to a higher degree between 2 and 4 weeks. PEG MD degradation was dependent on the addition of RGD and the amount of CMC.

Conclusions: Chemical and/or physical modifications of PEG hydrogels influenced matrix stability. PEG MD/RGD demonstrated an optimal balance between degradation time and integration into the surrounding soft and hard tissues. 


\section{Introduction}

Various guided bone regeneration (GBR) membranes were evaluated in the past to fulfill the clinician's needs. Non-resorbable membranes are documented to have long-term clinical success and were considered the gold standard in GBR procedures for many years (Benic and Hammerle, 2014). However, they are associated with multiple disadvantages including the need for removal at second stage and reveal a relatively high risk for soft tissue dehiscence. In order to overcome these issues, resorbable membranes made of native collagen were developed and presented similar long-term outcomes based on clinical studies (Jung et al., 2013). The lack of spacemaintenance and the need for a more time-consuming membrane shaping and adapting during surgery, led to the development of alternative materials, including the use of polyethylene hydrogels (PEGs). PEG hydrogels were used for various indications ranging from a biodegradable membrane for GBR (Jung et al., 2006; Jung et al., 2009a; Jung et al., 2009b), to a matrix for bone regeneration and to the use as a carrier for biologic mediators (Jung et al., 2007a; Jung et al., 2007b; Jung et al., 2008). When applied as a GBR membrane, clinical data demonstrated success up to 5 years, but shortcomings in terms of the initial soft tissue attachment, which in some cases led to transient soft tissue complications (Jung et al., 2015; Ramel et al., 2012). In order to facilitate cell attachment and reduce the number of early complications, modifications of the PEG hydrogels were evaluated. This included physical (changes in the network structure) and chemical modifications (addition of a bioadhesive motif like the Arginine-Glycine-Aspartic acid (RGD) for an improved cell adhesion and modifications of the viscosity by controlling the amount of carboxymethyl cellulose (CMC) (Dettin et al., 2005; Halstenberg et al., 2002; Park et al., 2004; Park et al., 2005; Shu et al., 2004). Preclinical data in rabbits and mini-pigs using various PEG hydrogels demonstrated that such modified hydrogels might lead to an increasing bone formation when RGD was added, associated with a relatively low stability and an enhanced turnover of the hydrogel (Thoma et al., 2011; Thoma et al., 2014). From a clinical point of view, when used as a GBR membrane, an optimal balance between an enhanced bone formation and long-term space-maintenance needs to be found. In order to validate the results from previous preclinical studies and to evaluate the influence of chemical and physical modifications of PEG 
hydrogels at relatively early healing time-points, the present study was designed. The aim of the present study was, therefore, to test whether or not the chemical and/or physical modifications of PEG hydrogels influence degradation time, matrix stability and soft and hard tissue integration in a rabbit cranial model. 


\section{Materials and methods}

\section{Animals}

The present experimental protocol was approved by the Animal Research Ethics Committee at the University of Zurich, Switzerland prior to the start of the study. In total, 28 adult (12 months old) New Zealand white rabbits, weighing between 3 and $4 \mathrm{~kg}$ were included. All animals were kept in a purposedesigned room for experimental animals and were fed a standard laboratory diet during the entire study period.

\section{Surgical procedure}

The protocol of the present study has already been described in detail (Thoma et al., 2011). In brief, anesthesia for the animals was initiated by injection of $65 \mathrm{mg} / \mathrm{kg}$ of ketamine and $4 \mathrm{mg} / \mathrm{kg}$ of xylazine and maintained with Isofluoran/O $\mathrm{O}_{2}$ (Aerane, Ohmeda Carbide Inc., Liberty Corner, NJ, USA). Subsequently, the surgical area was shaved and disinfected with iodophor for aseptic surgical conditions. Following a straight incision from the nasal bone to the midsagittal crest, the soft tissues including the periosteum were elevated (Fig. 1a). In order to simplify the histologic preparation, nine titanium pins (Frios ${ }^{\circledR}$, Dentsply Friadent, Mannheim, Germany) were placed, three at the mid-sagittal line and 6 laterally to the mid-sagittal line (Fig. 1b). In addition, linear bony defects were prepared using a small round bur (diameter $0.7 \mathrm{~mm}$ ) between the reference pins at the mid-sagittal line and the pins on the left and right sides (Fig. 1b).

The following six treatment modalities were then randomly assigned to the six sites (Fig. $1 \mathrm{c}-\mathrm{f}$ ):

1. a dense network PEG hydrogel (PEG HD) (MembraGel ${ }^{\circledR}$, Institut Straumann AG, Basel, Switzerland)

2. a medium-dense network PEG hydrogel (PEG MD) (Institut Straumann AG, Basel, Switzerland)

3. a medium-dense network PEG hydrogel modified with RGD (PEG MD/RGD) (Institut Straumann AG, Basel, Switzerland)

4. a medium-dense network PEG hydrogel modified with RGD without addition of CMC and according low viscosity (PEG MD/RGD_LV) (Institut Straumann AG, Basel, Switzerland)

5. a loose network PEG hydrogel modified with RGD (PEG LD/RGD) (Institut Straumann AG, Basel, Switzerland) 


\section{6. a collagen membrane (BG) (BioGide ${ }^{\circledR}$, Geistlich Pharma, Wolhusen, Switzerland)}

The preparation of the hydrogels has been described in previous publications (Thoma et al., 2011;

Thoma et al., 2014). In brief, the PEG hydrogels were prepared by mixing a multi-arm PEG with thiol end groups and a multi-arm PEG with acrylate end groups in an aqueous buffer system (triethanolamine/ $\mathrm{HCl}$ ) at physiological $\mathrm{pH}$. Carboxymethyl cellulose $(\mathrm{CMC}$ ) was added as a viscosity modifier to the buffer solutions to control the flow properties of the PEG solutions. For preparing the RGD containing PEG hydrogels (PEG MD/RGD; PEG MD/RG_LV; PEG LD/RDG), a peptide containing an integrin-binding RGD for cell adhesion was used and a cysteine group for connecting the peptide to a PEG-acrylate terminus. All in situ gelling PEG hydrogels were applied from a mixing syringe as a liquid over the bone. In order to standardize the hydrogel thickness to $1.5 \mathrm{~mm}$, preformed templates were placed on the bone and removed after the gelling process of the hydrogels (Fig. 1C). The BG membranes were trimmed to a rectangular shape and placed on the skull without fixation (Fig. 1b). Following the removal of the periosteum primary wound closure was obtained. The animals were sedated with barbiturates at $1(n=7), 2(n=7), 4(n=7)$, and 6 weeks $(n=7)$ and sacrificed with an overdose of Ketamine.

\section{Histological preparation}

All specimens were placed in a mixture of $2.5 \%$ glutaraldehyde, $2 \%$ paraformaldehyde, and $0.025 \%$ $\mathrm{CaCl}$ in $0.02 \mathrm{M} \mathrm{Na-cacodylate} \mathrm{buffer}$. Following fixation the tissue specimens were washed in $0.185 \mathrm{M}$ $\mathrm{Na}$-cacodylate buffer and radiographed to determine the exact cutting planes parallel and on the left and right side of the sagittal suture. The tissue blocks were then sectioned with a band-saw (EXAKT, Norderstedt, Germany) and postfixed in $1.33 \% \mathrm{OsO}_{4}$ buffered with $0.067 \mathrm{M} \mathrm{s}$-collidine. Following an overnight wash in $0.185 \mathrm{M} \mathrm{Na}$-cacodylate buffer, the specimens were dehydrated in ascending grades of alcohol and embedded in pure Epon. Three slices of about $1 \mathrm{~mm}$ in thickness were cut from each site and glued on empty Epon cylinders. The block-size was adjusted to include the full anteroposterior extension of the membranes. Finally, sections of $80 \mu \mathrm{m}$ in thickness were cut with a microtome (Reichert Ultracut E microtome, Leica Microsystems, Heerbrugg, Switzerland) and stained with toluidine blue or periodic acid-Schiff (PAS) and methylene blue-Azur II. 


\section{Descriptive histologic and histomorphometric analyses}

The histological samples were digitized using a stereoscope (Nikon Eclipse 90i, Nikon, Egg, Switzerland). For descriptive histologic analysis, the following parameters were analyzed: (i) form and appearance of the hydrogel/membrane, (ii) the interface between the connective tissue and the hydrogel/membrane, (iii) the interface between the hydrogel/membrane and the native bone, (iv) new bone formation surrounding and/or within the hydrogel/membrane, and ( $v$ ) the inflammatory response. For histomorphometric analysis, the images were analyzed using an image-processing program (Image J, NIH, Bethesda, USA). A standardized region of interest (ROI) was chosen extending from the bone defect into the soft tissue (Fig. 2a). The following parameters were calculated within the ROI: (i) new bone, (ii) old bone, iii) non-mineralized tissue, (iv) matrix/membrane, and $(v)$ background space. Two masked experienced examiners independently performed all the measurements.

\section{Statistical analysis}

All measured outcomes were summarized as means and standard deviations, and as medians and interquartile ranges. Mixed linear models were performed using the non-parametric Brunner-Langer method (Brunner and Langer, 1999). The level of significance was set at $\mathrm{p}<0.05$. Results from the models are expressed as adjusted 'means'. Further details are provided in the appendix. 


\section{Results}

All rabbits were healthy during the entire study period and neither systemic nor local adverse events were observed.

\section{Descriptive histology}

PEG HD

The PEG dense network hydrogel was intensely stained, had a semilunar shape and maintained the space up to the last sacrifice time-point ( 6 weeks). At 1 and 2 weeks, the hydrogel surface was smooth with few irregularities. An empty space surrounded the PEG network. At 4 weeks, the contact to the underlying bone and the subcutaneous soft tissue was more intimate. This observation was even more obvious at 6 weeks (Fig. 2b), demonstrating no empty space surrounding the PEG, but a close contact with the surrounding soft and hard tissues. Overall, only limited bone formation was observed underneath the hydrogel.

\section{PEG MD}

The PEG MD hydrogel was slightly stained and appeared to maintain the space up to 2 weeks (Fig. 2c). Degradation and remodeling processes started after 2 weeks and continued up to 6 weeks. An empty space between the membrane and the soft tissues was present during the first 2 weeks and disappeared gradually at 4 and 6 weeks. At the later time-points only few remnants could be identified within a newly formed connective tissues. Bone formation was limited and predominantly occurred underneath the hydrogel on top of the created defect.

PEG MD/RGD

The hydrogel was densely stained at 1 and 2 weeks. The borders of the hydrogel were in intimate contact with the surrounding connective tissue (Fig. 2d). The shape of the original hydrogel space was not maintained during 6 weeks. Mainly between 2 and 4 weeks, the hydrogel appeared to have collapsed and remodeled. At 4 and 6 weeks, only remnants surrounded by connective tissue were identified. The hydrogel remnants were still densely stained without a clear distinction to the covering soft tissue and the underlying bone.

PEG MD/RGD_LV 
The hydrogel was predominantly visible at 1 and 2 weeks. At these time-points, the space appeared to have been maintained and the hydrogel appeared to be intact. At 2 weeks, an empty space surrounded the PEG hydrogel, swelling and subsequent shrinkage had taken place. The borders of the hydrogel were distinct towards the covering soft tissues. The contact to the underlying bone was intimate with some limited bone formation visible at 2 weeks already. At 4 and 6 weeks, the space was still maintained, but connective tissue formation had taken place and started to replace this space, originally maintained by the hydrogel. The formation of new connective tissue was predominantly visible at 6 weeks.

\section{PEG LD/RGD}

The bulk of the looser network PEG-RGD network was intensively stained at 1 and 2 weeks. At these time-points, a small space surrounded the hydrogel, but less distinct than in the PEG HD and PEG MD groups. The border at 1 week was distinct and had only few irregularities (Fig. 2e), whereas at 2 weeks, the hydrogel had a more intimate contact with the surrounding tissues. At 4 and 6 weeks, no remnants of the hydrogel were observed. At 6 weeks, new bone and connective tissue formation had taken place and replaced most of the space originally maintained by the hydrogel. Bone formation was predominantly visible at 6 weeks, and mainly occurred within and on top of the created defect.

\section{$B G$}

The collagen membrane appeared to have maintained the shape and was in close contact to the underlying bone and the covering soft tissue already at 1 week (Fig. 2f). The bulk of the membrane was dominated with thick collagen fibers. At 4 and 6 weeks, the remodeling processes within the membrane and on the membrane's surface, made it difficult to clearly differentiate it from the surrounding tissues.

\section{Histomorphometric measurements}

All summarized data are shown in table 1 . The histomorphometric analysis revealed only minimal, but increasing new bone formation over the course of 6 weeks for all matrices/membranes. At 6 weeks, the largest adjusted mean amount of newly formed bone (\% area within the ROI) was observed for PEG MD 2.4\% (95\% CI: $0.9 \%-10.3 \%$ ) followed by BG 
$2.3 \%(95 \%$ CI: $0.9 \%-8.7 \%$ ) and by PEG HD $2.1 \%$ (95\% CI: $0.7 \%-4.8 \%$ ). None of the differences between the 6 groups were statistically significant at any time-point $(p>0.05)$, except between BG and PEG HD at 1 week, favoring BG $(p=0.024)$. In terms of residual matrix/membrane, individual differences between the matrices/membranes were observed (Fig. 3). The largest adjusted mean area was calculated for PEG MD/RGD 61.0\% (95\% CI: 43.2\%73.9\%) and PEG HD 47.2\% (95\% CI: 32.8\%-63.8\%) at 1 week, and at 6 weeks for PEG HD 23.4\% (95\% CI: $10.3 \%-49.8 \%$ ) followed by PEG MD/RGD $17.1 \%$ (95\% CI: $6.5 \%-30.0 \%$ ). PEG HD revealed high values of residual matrix at all time-points starting with $47.2 \%$ (95\% CI: $32.8 \%-63.8 \%)$ at 1 week and ending with $23.4 \%(95 \% \mathrm{CI}: 10.3 \%-49.8 \%)$ at 6 weeks. PEG MD degradation was dependent on the addition of RGD and the amount of CMC. The adjusted mean matrix area for PEG MD/RGD_LV demonstrated an increase between the first week with $22.5 \%$ (95\% CI: $17.0 \%-42.8 \%$ ), to the second and fourth week with $40.9 \%$ (95\% CI: $30.7 \%-59.3 \%$ ) and $36.8 \%(95 \% \mathrm{CI}: 18.8 \%-67.2 \%)$, respectively, but then a decrease to $8.3 \%$ ( $95 \% \mathrm{CI}$ : $3.9 \%-21.0 \%$ ) at 6 weeks. The hydrogel with the loosest network (PEG LD/RGD) was stable the first two weeks and then decreased continuously in its dimension with a final area of $8.3 \%$ (95\% $\mathrm{CI}: 3.2 \%-21.0 \%)$. The collagen membrane (BG) revealed a continuous degradation over time with $21.2 \%(95 \% \mathrm{CI}: 15.9 \%-37.0 \%)$ at 1 week and $8.5 \%(95 \% \mathrm{CI}: 3.2 \%-21.9 \%)$ at 6 weeks. The differences between PEG MD/RGD and PEG MD/RGD_LV $(p=0.016)$, PEG LD/RGD $(p=0.022)$, and BG $(p=0.009)$ were statistically significant at 1 week. At 4 weeks, the differences between PEG HD and BG $(p=0.006)$, PEG LD/RGD $(p=0.028)$, PEG MD/RGD $(p=0.004)$ were statistically significant. All other comparisons between the groups did not reveal statistically significant differences at any time-point $(p>0.05)$. Comparisons of these outcomes at 1 week and 6 weeks are shown in figure 1 in the appendix.

The $p$-values for the global comparison for the factors treatment, time point and interaction of treatment by time point when the outcome was the matrix/membrane were $p<0.0001, p<0.001$ and $p=0.033$ respectively. This result reflects observations from figure 3 . Results for all global comparisons are given in table 1 in the appendix. 


\section{Discussion}

The present experimental study revealed based on histomorphometric measurements that chemical and/or physical modifications of PEG hydrogels predominantly influenced matrix stability and degradation time. This was demonstrated by i) the dense network PEG hydrogel (PEG HD) being almost stable over time, ii) the mid-range dense PEG hydrogel (PEG MD) being stable up to 4 weeks and then degrading slightly over time and, iii) the loose network PEG hydrogel (PEG LD) degradation to the highest extent after being stable for 2 weeks. In addition, modifications of PEG MD seemed to change the characteristics of degradation within the first four weeks.

The dense network PEG hydrogel (PEG HD) was the most stable material in terms of degradation time and volume maintenance. This was predominantly demonstrated by maintaining a semilunar shape over the entire study period. This type of hydrogel membrane has been evaluated in various preclinical and clinical studies for a number of indications (Jung et al., 2006; Jung et al., 2009a; Jung et al., 2009b), and also for basic requirements of GBR membranes such as a barrier function and cell occlusiveness. In an experimental study in rats, using a subcutaneous pouch model, PEG HD demonstrated a barrier function up to 6 months and cell occlusiveness up to 4 months (Wechsler et al., 2008). These long-term data are supported by the present study demonstrating the same membrane stability with a minimal decrease in thickness over time. This long-term stability might be due to the high network density, which may further explain the observed cell occlusiveness of up to 4 months (Wechsler et al., 2008). As reported earlier, one of the basic principles of GBR is space maintenance, but at the same time, a barrier membrane needs to be semi-permeable. The PEG HD membrane appears to have a rather strict cell occlusiveness. This is underlined by findings of the present study that showed a clear and distinct border towards the covering soft tissues. A close and more intimate contact was only observed at 4 weeks in this rabbit model. This histologic finding, clinically translated into a lack of an attachment between the barrier membrane and the covering soft tissue flap, may in part be responsible for a relatively high rate of early wound dehiscences (Jung et al., 
2009a). In order to overcome such clinical difficulties, the option exists to modify the existing hydrogels. One of the options is to reduce the network density. Such a network might allow an earlier ingrowth of connective tissue. In the present study, three groups of a mid-range dense network PEG hydrogel (PEG MD) were tested. The native PEG MD demonstrated a reduced stability occupying a smaller area on top of the rabbit skull up to 4 weeks. Between 4 and 6 weeks, matrix/membrane degradation was highly increased. However, even with PEG MD, 2 weeks were needed until the empty space between the soft tissues and the hydrogel started to disappear and a more intimate contact was obtained.

Apart from changing the hydrogel network, the addition of an RGD sequence has been shown to improve the contact between membranes and soft tissues at week one and two. Furthermore, the degradation seems to be accelerated by RGD between two and four weeks as shown by PEG MD/RGD when compared to the native PEG MD. The properties of hydrogels with RGD regarding degradation and contact to surrounding tissues seem to be beneficial. The addition of RGD therefore resulted in enhanced soft tissue integration (Dahlin et al., 2014).

By reducing the amount of CMC from 2.2\% to 0\% (PEG MD/RGD_LV), the hydrogel formulation becomes less viscous and the clinical handling is more difficult in terms of controlling the area, where the matrix/membrane is applied. In the present study, a framework was used to standardize the application of all PEG hydrogels. A reduction of the CMC content, however, reduced the membrane stability, which therefore limits PEG volume maintenance over time. In addition, it has been reported that CMC decreases osteoclastogenesis, whereas osteoblastogenesis remains unaffected (Agis et al., 2010). The effect of CMC on bone formation and remodeling could not be shown in the present study.

The loosest network PEG LD/RGD was able to maintain the space for two weeks only. Thereafter, degradation started accompanied by a reduction of the membrane volume and a consecutive loss of PEG volume maintenance. With the beginning degradation at 2 weeks, one might assume that the cell occlusiveness will also be reduced. In contrast, the contact towards the surrounding soft tissues was very intimate already at 1 week similar to previously published data (Thoma et al., 
2011). Nevertheless, successful and predictable bone regeneration can only be achieved through continuous space maintenance and cell occlusiveness. Therefore the loosest network PEG LD/RGD might not be an ideal candidate as a membrane, but rather serve as a matrix.

The collagen membrane (BG) started with a lower percentage of residual membrane within the ROI compared to PEG hydrogel layers. This was due to the fact that the thickness of the BG could not be changed unlike for the PEG hydrogels. The favorable integration and intimate contact to the surrounding tissues was histologically visible during the entire observation period. The degradation process of the collagen membrane was accompanied by a visible ingrowth of connective tissue and a continuous integration into the surrounding tissues similar to a previous experiment (Ghanaati et al., 2011). This remains a main contrast compared to the PEG hydrogels, which are never infiltrated by cells. The hydrogels seem to be encapsulated until their complete degradation, and body's own tissues take the maintained space thereafter. Earlier studies reported stronger signs of inflammation around PEG hydrogels compared to collagen membranes (Jung et al., 2009b). In general, only a limited number of inflammatory cells were detected close to the PEG matrices/membranes.

Limitations of the study are predominantly due to i) the standardization of the thickness during surgery and, ii) the histological processing of the PEG hydrogels. Standardization of the matrix/membrane thickness was optimized using preformed templates compared to a previous study (Thoma et al., 2011). Varying viscosities of the PEG hydrogels still presented challenges. In addition, the thickness of the control native collagen membrane was smaller, but kept into account when performing the analyses and interpretation of the results. Moreover, similar to the previous study, the PEG hydrogels appeared to swell during the healing period. This in combination with the histologic processing led to some detachment from the surrounding soft tissues.

The present study illustrates the potential of modifications of polyethylene glycol hydrogels. Volume maintenance as well as tissue integration can be regulated by changing the network density. In case of a looser network structure, the contact to the surrounding soft tissues was 
more intimate. Clinically, one might speculate that this favorable biological tissue integration could result in a lower rate of early wound dehiscence. In addition, RGD improved the contact to the surrounding tissues and accelerated the degradation of the membrane/matrix. PEG MD/RGD appeared to have an optimal balance between PEG volume maintenance, hydrogel degradation and soft tissue integration. 


\section{Conclusions}

Chemical and/or physical modifications of PEG hydrogels predominantly influenced matrix stability, degradation time and integration into the surrounding soft and hard tissues. The medium-dense network PEG hydrogel (PEG MD/RGD) demonstrated an optimal balance between membrane stability, degradation time and tissue integration. This membrane could serve as a favorable candidate for a synthetic GBR membrane in the future. 


\section{Acknowledgements and conflict of interest}

The study was supported by the Clinic of Fixed and Removable Prosthodontics and Dental Material Science, University of Zurich, Switzerland and a research grant of Institut Straumann AG, Basel, Switzerland. The authors would like to thank the team at Harlan Laboratories, Itingen, Switzerland for the preparation of the histological slides and Sonja Hitz, Clinic of Fixed and Removable Prosthodontics and Dental Material Science, University of Zurich for her help and expertise in the preparation of the histomorphometric analyses. The help of Leticia Grize, PhD (Swiss Tropical and Public Health Institute, Department of Epidemiology and Public Health, Basel, Switzerland) for performing the statistical analysis is highly acknowledged. The authors report no conflicts of interests. 


\section{Legends: Tables and Figures}

Table 1. Descriptive statistics (mean, standard deviation, median and interquartile range in \%) of histomorphometric measurements within the region of interest by matrix/membrane and by time-point. SD = standard deviation; $\mathrm{IQR}=$ interquartile range; $\mathrm{PEG} \mathrm{HD}=$ a dense network $\mathrm{PEG}$ hydrogel; PEG MD = a medium-dense network PEG hydrogel; PEG MD/RGD = a medium-dense network PEG hydrogel modified with RGD; PEG MD/RGD_LV = a medium-dense network PEG hydrogel modified with RGD without addition of CMC and according low viscosity; PEG LD/RGD $=$ a loose network PEG hydrogel modified with RGD; BG = a collagen membrane

Figure 1 (a-f). Clinical pictures of flap elevation (1a), creation of bony defects marked by reference pins (1b), followed by randomly assigned membrane application (1c-f). The treatments are the following (starting at the upper left, then clockwise): BG = a collagen membrane; PEG LD/RGD = a loose network PEG hydrogel modified with RGD; PEG MD = a medium-dense network PEG hydrogel; PEG MD/RGD = a medium-dense network PEG hydrogel modified with RGD; PEG HD = a dense network PEG hydrogel; PEG MD/RGD_LV = a medium-dense network PEG hydrogel modified with RGD without addition of CMC and according low viscosity

Figure 2a. Region of interest (ROI) (green rectangle) containing the matrix/membrane (M) material and the surrounding connective tissue (CT) and the underlying bone (B).

Figure 2b. PEG HD at 6 weeks: The hydrogel (M) is densely stained and shows no signs of degradation. Due to shrinkage and a delayed tissue integration, the matrix is surrounded by an empty space. $\mathrm{B}=$ bone; $\mathrm{CT}=$ connective tissue

Figure 2c. PEG MD at 2 weeks: The medium dense hydrogel $(M)$ is densely stained. The soft tissues are detached from the matrix' surface. $\mathrm{B}=$ bone; $\mathrm{CT}=$ connective tissue 
Figure 2d. PEG MD/RGD at 2 weeks: the matrix (M) demonstrates an intimate contact to the surrounding soft tissues. $\mathrm{B}=$ bone; $\mathrm{CT}=$ connective tissue

Figure 2e. PEG LD/RGD at 1 week: The contact to the surrounding tissues is intimate at this time point. $\mathrm{M}=$ matrix/membrane; $\mathrm{B}=$ bone; $\mathrm{CT}=$ connective tissue

Figure 2f. BG at 1 week: The collagen membrane (M) demonstrates an intimate contact towards the underlying bone. Bundles of collagen fibers representing the membranes network are densely stained and surrounded by non-mineralized tissue. $\mathrm{B}=$ bone; $\mathrm{CT}=$ connective tissue

Figure 3. Membrane degradation over time measured in percentage by terms of residual membrane. The lines represent a linear smoother. PEG HD = a dense network PEG hydrogel; PEG MD = a medium-dense network PEG hydrogel; PEG MD/RGD = a medium-dense network PEG hydrogel modified with RGD; PEG MD/RGD_LV = a medium-dense network PEG hydrogel modified with RGD without addition of CMC and according low viscosity; PEG LD/RGD = a loose network PEG hydrogel modified with RGD; BG = a collagen membrane (BG)

\section{FOR THE APPENDIX:}

Appendix 1: Detailed statistical methods.

Appendix 2: Overall ${ }^{\S}$ effect of treatment, time and interaction between time and treatment.

Appendix 3: Association between outcomes and treatments: (a) for membrane/matrix at 1 week and 6 weeks and (b) for new bone at 1 week and 6 weeks. Associations are adjusted by the effect of animal (random effect) and position and side (fixed effects). The black square indicates the adjusted means and the whiskers the $95 \%$ confidence intervals. 
Appendix 4: Sometimes, inflammatory cells can be found within the soft tissues next to PEG materials as seen in this illustration.

Appendix 5: At higher magnification, new bone formation within the defect and an intimate contact of PEG and bone are visible (PEG HD at 6 weeks).

Appendix 6: PEG HD, a high density network PEG hydrogel at 2 weeks. The attachment to the underlying bone (B) seems to be more favorable than towards the soft tissue (CT). Furthermore, this illustration indicates the problem of shrinkage of PEG materials during the histologic process, leaving an impression of its original shape in the soft tissue.

Appendix 7: PEG MD RGD, a medium-dense network PEG hydrogel modified with RGD shows an intimate contact to the underlying bone (B) as well as to the connective tissue (CT) at 4 weeks.

Appendix 8: At 4 weeks, PEG MD/RGD_LV, a medium-dense network PEG hydrogel modified with RGD without addition of CMC and according low viscosity shows already clear signs of degradation. An ingrowth of the connective tissue (CT) is visible. $B=$ bone

Appendix 9: At 4 weeks, PEG LD, a loose network PEG hydrogel is almost completely degraded. Newly formed bone (NB) is visible underneath the membrane. $\mathrm{CT}=$ connective tissue

Appendix 10: Only remnants of the collagen membrane (BG) are visible at 6 weeks. Newly formed bone (NB) can be found underneath the membrane. $\mathrm{CT}=$ connective tissue 


\section{References}

Agis H, Beirer B, Watzek G, Gruber R (2010). Effects of carboxymethylcellulose and hydroxypropylmethylcellulose on the differentiation and activity of osteoclasts and osteoblasts. $J$ Biomed Mater Res A 95(2):504-509.

Benic GI, Hammerle CH (2014). Horizontal bone augmentation by means of guided bone regeneration. Periodontol 2000 66(1):13-40.

Brunner E, Langer F (1999). Non-parametric analysis of longitudinal data. (In German). In: Oldenburgverlag, München.

Dahlin C, Johansson A, Hoffman M, Molenberg A (2014). Early biocompatibility of poly (ethylene glycol) hydrogel barrier materials for guided bone regeneration. An in vitro study using human gingival fibroblasts (HGF-1). Clin Oral Implants Res 25(1):16-20.

Dettin M, Conconi MT, Gambaretto R, Bagno A, Di Bello C, Menti AM et al. (2005). Effect of synthetic peptides on osteoblast adhesion. Biomaterials 26(22):4507-4515.

Ghanaati S, Schlee M, Webber MJ, Willershausen I, Barbeck M, Balic E et al. (2011). Evaluation of the tissue reaction to a new bilayered collagen matrix in vivo and its translation to the clinic. Biomed Mater 6(1):015010.

Halstenberg S, Panitch A, Rizzi S, Hall H, Hubbell JA (2002). Biologically engineered proteingraft-poly(ethylene glycol) hydrogels: a cell adhesive and plasmin-degradable biosynthetic material for tissue repair. Biomacromolecules 3(4):710-723. 
Jung RE, Zwahlen R, Weber FE, Molenberg A, van Lenthe GH, Hammerle CH (2006). Evaluation of an in situ formed synthetic hydrogel as a biodegradable membrane for guided bone regeneration. Clin Oral Implants Res 17(4):426-433.

Jung RE, Cochran DL, Domken O, Seibl R, Jones AA, Buser D et al. (2007a). The effect of matrix bound parathyroid hormone on bone regeneration. Clin Oral Implants Res 18(3):319-325.

Jung RE, Hammerle $\mathrm{CH}$, Kokovic V, Weber FE (2007b). Bone regeneration using a synthetic matrix containing a parathyroid hormone peptide combined with a grafting material. Int J Oral Maxillofac Implants 22(2):258-266.

Jung RE, Weber FE, Thoma DS, Ehrbar M, Cochran DL, Hammerle CH (2008). Bone morphogenetic protein-2 enhances bone formation when delivered by a synthetic matrix containing hydroxyapatite/tricalciumphosphate. Clin Oral Implants Res 19(2):188-195.

Jung RE, Halg GA, Thoma DS, Hammerle CH (2009a). A randomized, controlled clinical trial to evaluate a new membrane for guided bone regeneration around dental implants. Clin Oral Implants Res 20(2):162-168.

Jung RE, Lecloux G, Rompen E, Ramel CF, Buser D, Hammerle CH (2009b). A feasibility study evaluating an in situ formed synthetic biodegradable membrane for guided bone regeneration in dogs. Clin Oral Implants Res 20(2):151-161.

Jung RE, Fenner N, Hammerle CH, Zitzmann NU (2013). Long-term outcome of implants placed with guided bone regeneration (GBR) using resorbable and non-resorbable membranes after 1214 years. Clin Oral Implants Res 24(10):1065-1073.

Jung RE, Benic GI, Scherrer D, Hammerle CH (2015). Cone beam computed tomography evaluation of regenerated buccal bone 5 years after simultaneous implant placement and guided 
bone regeneration procedures--a randomized, controlled clinical trial. Clin Oral Implants Res 26(1):28-34.

Park KH, Kim MH, Park SH, Lee HJ, Kim IK, Chung HM (2004). Synthesis of Arg-Gly-Asp (RGD) sequence conjugated thermo-reversible gel via the PEG spacer arm as an extracellular matrix for a pheochromocytoma cell (PC12) culture. Biosci Biotechnol Biochem 68(11):2224-2229.

Park KH, Na K, Chung HM (2005). Enhancement of the adhesion of fibroblasts by peptide containing an Arg-Gly-Asp sequence with poly(ethylene glycol) into a thermo-reversible hydrogel as a synthetic extracellular matrix. Biotechnol Lett 27(4):227-231.

Ramel CF, Wismeijer DA, Hammerle CH, Jung RE (2012). A randomized, controlled clinical evaluation of a synthetic gel membrane for guided bone regeneration around dental implants: clinical and radiologic 1- and 3-year results. Int J Oral Maxillofac Implants 27(2):435-441.

Shu XZ, Ghosh K, Liu Y, Palumbo FS, Luo Y, Clark RA et al. (2004). Attachment and spreading of fibroblasts on an RGD peptide-modified injectable hyaluronan hydrogel. J Biomed Mater Res A $68(2): 365-375$.

Thoma DS, Subramani K, Weber FE, Luder HU, Hammerle CH, Jung RE (2011). Biodegradation, soft and hard tissue integration of various polyethylene glycol hydrogels: a histomorphometric study in rabbits. Clin Oral Implants Res 22(11):1247-1254.

Thoma DS, Schneider D, Mir-Mari J, Hammerle CH, Gemperli AC, Molenberg A et al. (2014). Biodegradation and bone formation of various polyethylene glycol hydrogels in acute and chronic sites in mini-pigs. Clin Oral Implants Res 25(4):511-521.

Wechsler S, Fehr D, Molenberg A, Raeber G, Schense JC, Weber FE (2008). A novel, tissue occlusive poly(ethylene glycol) hydrogel material. J Biomed Mater Res A 85(2):285-292. 


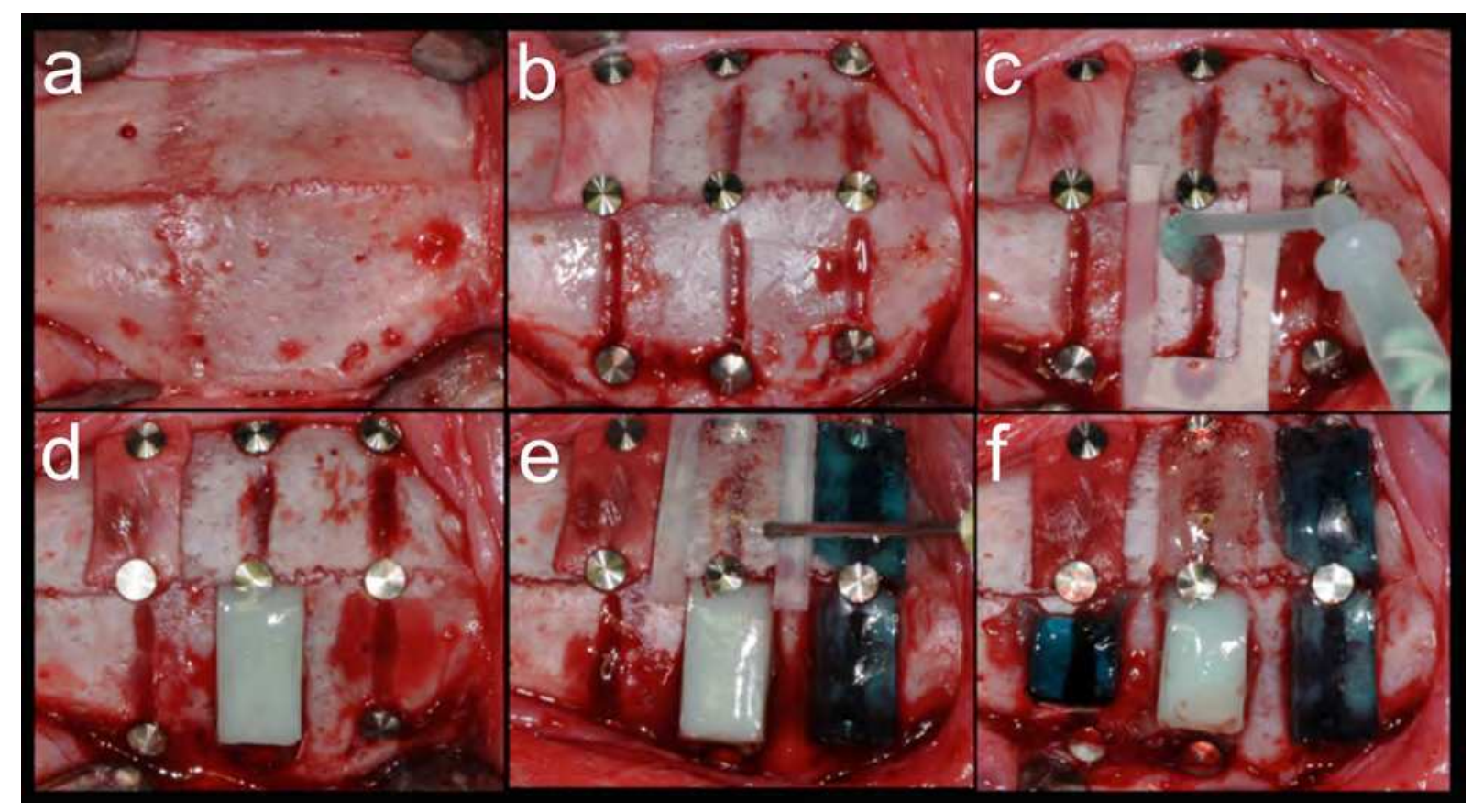

Figure 1

a)

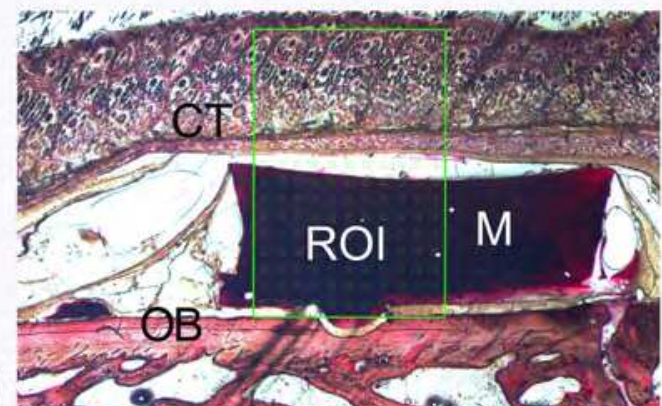

c)


b)

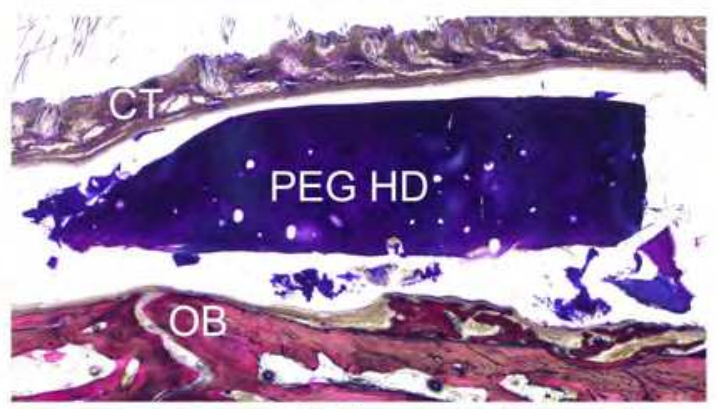

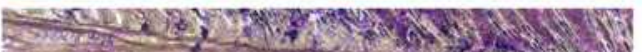
p

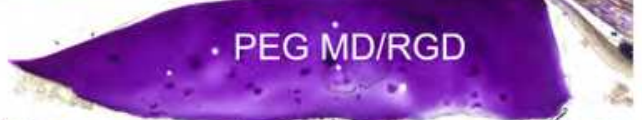

d)
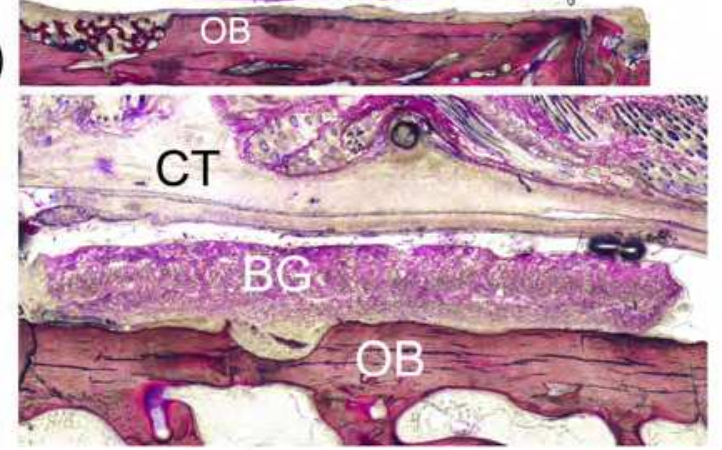

e)

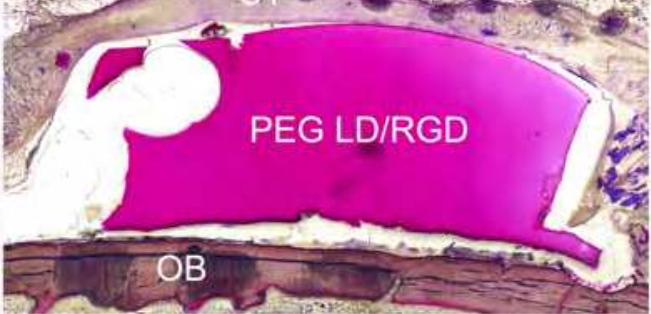

f)

Figure 2 


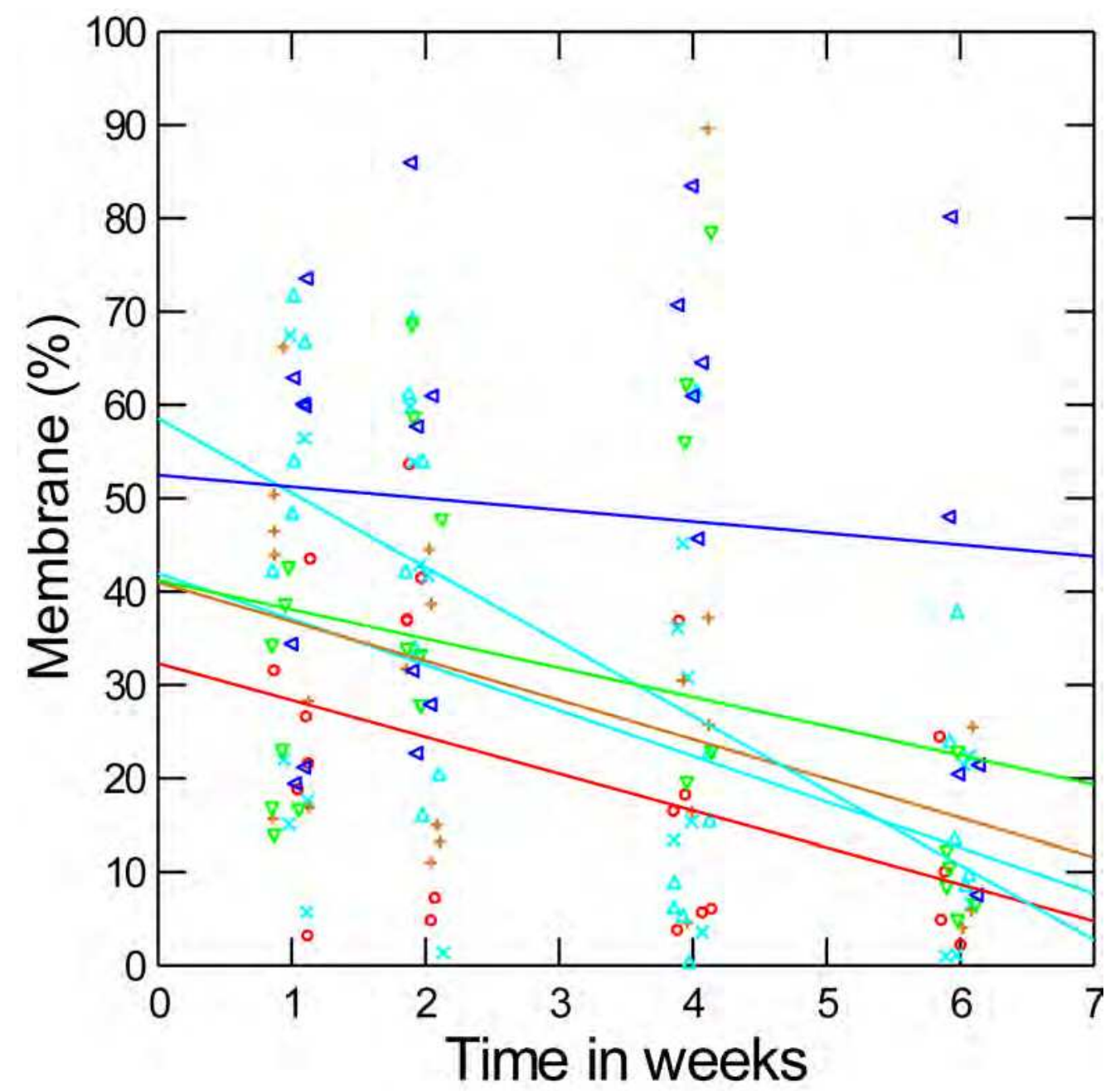

Membrane name (treatment)

○ BG

$\times$ PEGLD/RGD

+ PEG MD

$\triangle$ PEG MD/RGD

$\nabla$ PEG MD/RGD_LV

$\triangleleft$ PEGHD

Figure 3 
Table 1. Descriptive statistics (mean, standard deviation, median and interquartile range in \%) for the histomorphometric measurements within the region of interest by treatment and time point

\begin{tabular}{|c|c|c|c|c|c|c|}
\hline \multirow{2}{*}{ Outcome } & \multirow{2}{*}{ Membrane type } & \multirow[t]{2}{*}{ Parameter } & \multicolumn{4}{|c|}{ Time point } \\
\hline & & & 1 week & 2 weeks & 4 weeks & 6 weeks \\
\hline \multirow{7}{*}{$\begin{array}{l}\text { Connective } \\
\text { Tissue }\end{array}$} & BG & $\mathrm{n}$ & 6 & 6 & 6 & 4 \\
\hline & & $\begin{array}{c}\text { Mean } \pm \text { SD } \\
\text { Median (IQR) }\end{array}$ & $\begin{array}{c}47.3 \pm 32.0 \\
37.5(19.3,76.7)\end{array}$ & $\begin{array}{c}44.8 \pm 19.8 \\
51.4(35.2,60.8)\end{array}$ & $\begin{array}{c}34.6 \pm 17.1 \\
37.2(15.9,48.6)\end{array}$ & $\begin{array}{c}19.8 \pm 3.7 \\
18.5(17.6,22.0)\end{array}$ \\
\hline & PEG LD/RGD & $\begin{array}{c}\mathrm{n} \\
\text { Mean } \pm \text { SD } \\
\text { Median (IQR) }\end{array}$ & $\begin{array}{c}6 \\
36.2 \pm 17.3 \\
30.2(25.0,41.5)\end{array}$ & $\begin{array}{c}5 \\
33.8 \quad \pm 11.4 \\
31.3(29.5,43.8)\end{array}$ & $\begin{array}{c}6 \\
30.9 \pm 18.8 \\
27.9(15.3,38.3)\end{array}$ & $\begin{array}{c}5 \\
21.3 \pm 10.9 \\
17.9(12.6,28.7)\end{array}$ \\
\hline & PEG MD & $\begin{array}{c}\mathrm{n} \\
\text { Mean } \pm \mathrm{SD} \\
\text { Median (IQR) }\end{array}$ & $\begin{array}{c}7 \\
45.0 \pm 20.0 \\
46.0(29.5,68.8) \\
\end{array}$ & $\begin{array}{c}6 \\
37.1 \pm 15.2 \\
31.5(25.0,46.0) \\
\end{array}$ & $\begin{array}{c}6 \\
25.0 \pm 16.1 \\
27.8(8.0,36.4) \\
\end{array}$ & $\begin{array}{c}4 \\
33.3 \pm 31.8 \\
21.9(15.2,51.3) \\
\end{array}$ \\
\hline & PEG MD/RGD & $\begin{array}{c}\mathrm{n} \\
\text { Mean } \pm \text { SD } \\
\text { Median (IQR) }\end{array}$ & $\begin{array}{c}5 \\
25.4 \pm 10.7 \\
31.8(17.0,33.0) \\
\end{array}$ & $\begin{array}{c}7 \\
41.6 \pm 22.1 \\
29.0(19.3,64.5) \\
\end{array}$ & $\begin{array}{c}7 \\
25.0 \pm 13.0 \\
25.6(13.1,35.8)\end{array}$ & $\begin{array}{c}5 \\
24.5 \pm 25.1 \\
14.2(12.1,15.6)\end{array}$ \\
\hline & $\begin{array}{l}\text { PEG } \\
\text { MD/RGD_LV }\end{array}$ & $\begin{array}{c}\mathrm{n} \\
\text { Mean } \pm \mathrm{SD} \\
\text { Median (IQR) }\end{array}$ & $\begin{array}{c}7 \\
47.7 \pm 21.6 \\
47.7(25,63.1) \\
\end{array}$ & $\begin{array}{c}6 \\
42.7 \pm 17.6 \\
42.0(29.0,58.9) \\
\end{array}$ & $\begin{array}{c}5 \\
24.3 \pm 8.1 \\
19.9(19.3,25.3) \\
\end{array}$ & $\begin{array}{c}6 \\
31.3 \pm 13.5 \\
34.3(16.5,42.0) \\
\end{array}$ \\
\hline & PEG HD & $\begin{array}{c}\mathrm{n} \\
\text { Mean } \pm \mathrm{SD} \\
\text { Median (IQR) }\end{array}$ & $\begin{array}{c}7 \\
32.3 \pm 24.5 \\
25.6(9.1,54.5)\end{array}$ & $\begin{array}{c}6 \\
32.9 \pm 22.5 \\
30.4(13.6,35.8)\end{array}$ & $\begin{array}{c}5 \\
26.9 \pm 12.8 \\
24.4(18.5,33.0)\end{array}$ & $\begin{array}{c}5 \\
34.3 \pm 24.2 \\
25.0(17.6,59.7)\end{array}$ \\
\hline \multirow[t]{6}{*}{ Matrix/Membrane } & BG & $\begin{array}{c}\mathrm{n} \\
\text { Mean } \pm \mathrm{SD} \\
\text { Median (IQR) }\end{array}$ & $\begin{array}{c}6 \\
23.7 \pm 12.7 \\
23.0(18.2,30.7) \\
\end{array}$ & $\begin{array}{c}6 \\
30.1 \pm 19.2 \\
36.4(6.8,42.0) \\
\end{array}$ & $\begin{array}{c}6 \\
14.0 \pm 11.8 \\
11.2(4.5,18.8) \\
\end{array}$ & $\begin{array}{c}4 \\
10.1 \pm 11.4 \\
7.2(2.0,18.1) \\
\end{array}$ \\
\hline & PEG LD/RGD & $\begin{array}{c}\mathrm{n} \\
\text { Mean } \pm \mathrm{SD} \\
\text { Median (IQR) } \\
\end{array}$ & $\begin{array}{c}6 \\
30.8 \pm 26.2 \\
19.5(14.2,57.3) \\
\end{array}$ & $\begin{array}{c}5 \\
40.1 \pm 23.9 \\
44.9(39.6,55.1) \\
\end{array}$ & $\begin{array}{c}6 \\
24.1 \pm 16.1 \\
22.0(11.9,36.4) \\
\end{array}$ & $\begin{array}{c}5 \\
10.8 \pm 10.8 \\
6.8(2.7,21.0) \\
\end{array}$ \\
\hline & PEG MD & $\begin{array}{c}\mathrm{n} \\
\text { Mean } \pm \text { SD } \\
\text { Median (IQR) }\end{array}$ & $\begin{array}{c}7 \\
37.7 \pm 18.7 \\
43.2(17.0,51.4) \\
\end{array}$ & $\begin{array}{c}6 \\
25.9 \pm 14.2 \\
23.9(13.1,37.5)\end{array}$ & $\begin{array}{c}6 \\
34.4 \pm 30.0 \\
27.7(16.2,38.6)\end{array}$ & $\begin{array}{c}4 \\
8.7 \pm 11.1 \\
4.8(2.0,15.3) \\
\end{array}$ \\
\hline & PEG MD/RGD & $\begin{array}{c}\mathrm{n} \\
\text { Mean } \pm \mathrm{SD} \\
\text { Median (IQR) } \\
\end{array}$ & $\begin{array}{c}5 \\
57.0 \pm 12.5 \\
55.4(47.7,64.8) \\
\end{array}$ & $\begin{array}{c}7 \\
43.1 \pm 20.3 \\
40.9(22.4,62.5) \\
\end{array}$ & $\begin{array}{c}7 \\
17.6 \pm 21.5 \\
10.2(4.0,23.9) \\
\end{array}$ & $\begin{array}{c}5 \\
18.6 \pm 12.6 \\
14.2(9.8,24.4) \\
\end{array}$ \\
\hline & $\begin{array}{l}\text { PEG } \\
\text { MD/RGD_LV }\end{array}$ & $\begin{array}{c}\mathrm{n} \\
\text { Mean } \pm \text { SD } \\
\text { Median (IQR) }\end{array}$ & $\begin{array}{c}7 \\
26.4 \pm 11.0 \\
22.1(17.0,36.3) \\
\end{array}$ & $\begin{array}{c}6 \\
44.8 \pm 15.7 \\
40.9(33.5,56.8)\end{array}$ & $\begin{array}{c}5 \\
46.6 \pm 25.6 \\
54.2(21.0,62.2)\end{array}$ & $\begin{array}{c}6 \\
9.8 \pm 6.4 \\
8.5(5.7,11.4) \\
\end{array}$ \\
\hline & PEG HD & $\begin{array}{c}n \\
\text { Mean } \pm \text { SD } \\
\text { Median (IQR) }\end{array}$ & $\begin{array}{c}7 \\
47.2 \pm 21.9 \\
59.7(21.0,63.6) \\
\end{array}$ & $\begin{array}{c}6 \\
47.7 \pm 24.4 \\
46.0(27.8,59.7) \\
\end{array}$ & $\begin{array}{c}5 \\
64.5 \pm 14.0 \\
65.9(59.9,69.9) \\
\end{array}$ & $\begin{array}{c}5 \\
36.5 \pm 28.5 \\
23.3(21.0,49.8) \\
\end{array}$ \\
\hline \multirow[t]{12}{*}{ New bone } & BG & $\begin{array}{c}\mathrm{n} \\
\text { Mean } \pm \text { SD } \\
\text { Median (IQR) }\end{array}$ & $\begin{array}{c}6 \\
0.6 \pm 0.5 \\
0.6(0.3,1.1) \\
\end{array}$ & $\begin{array}{c}6 \\
7.4 \pm 5.8 \\
8.5(1.7,12.5) \\
\end{array}$ & $\begin{array}{c}6 \\
3.0 \pm 1.4 \\
3.1(2.6,4.3) \\
\end{array}$ & $\begin{array}{c}4 \\
4.0 \pm 3.3 \\
3.4(1.6,6.5) \\
\end{array}$ \\
\hline & PEG LD/RGD & $\begin{array}{c}\mathrm{n} \\
\text { Mean } \pm \mathrm{SD} \\
\text { Median (IQR) }\end{array}$ & $\begin{array}{c}6 \\
0.9 \pm 1.1 \\
0.6(0.0,1.1) \\
\end{array}$ & $\begin{array}{c}5 \\
10.6 \pm 21.4 \\
0.6(0,3.7) \\
\end{array}$ & $\begin{array}{c}6 \\
2.8 \pm 3.4 \\
1.7(0.6,3.7) \\
\end{array}$ & $\begin{array}{c}5 \\
4.1 \pm 6.3 \\
1.7(1.7,1.7) \\
\end{array}$ \\
\hline & PEG MD & $\begin{array}{c}\mathrm{n} \\
\text { Mean } \pm \mathrm{SD} \\
\text { Median (IQR) }\end{array}$ & $\begin{array}{c}7 \\
0.3 \pm 0.4 \\
0.1(0,0.6) \\
\end{array}$ & $\begin{array}{c}6 \\
5.6 \pm 8.7 \\
2.3(0.6,5.7) \\
\end{array}$ & $\begin{array}{c}6 \\
3.3 \pm 4.3 \\
1.7(0.6,4.3) \\
\end{array}$ & $\begin{array}{c}4 \\
7.1 \pm 8.4 \\
3.3(2.4,11.8) \\
\end{array}$ \\
\hline & PEG MD/RGD & $\begin{array}{c}\mathrm{n} \\
\text { Mean } \pm \text { SD } \\
\text { Median (IQR) }\end{array}$ & $\begin{array}{c}5 \\
0.3 \pm 0.4 \\
0(0,0.6)\end{array}$ & $\begin{array}{c}7 \\
1.8 \pm 3.1 \\
0.6(0,2.3) \\
\end{array}$ & $\begin{array}{c}7 \\
1.4 \pm 1.6 \\
1.1(0.2,1.7)\end{array}$ & $\begin{array}{c}5 \\
1.0 \pm 1.3 \\
0.6(0.6,0.9)\end{array}$ \\
\hline & $\begin{array}{l}\text { PEG } \\
\text { MD/RGD_LV }\end{array}$ & $\begin{array}{c}\mathrm{n} \\
\text { Mean } \pm \text { SD } \\
\text { Median (IQR) }\end{array}$ & $\begin{array}{c}7 \\
0.2 \pm 0.3 \\
0(0,0.6) \\
\end{array}$ & $\begin{array}{c}6 \\
1.2 \pm 0.6 \\
1.4(0.8,1.7) \\
\end{array}$ & $\begin{array}{c}5 \\
2.3 \pm 3.4 \\
1.1(0,2.0) \\
\end{array}$ & $\begin{array}{c}6 \\
5.3 \pm 7.4 \\
1.1(0.3,11.2) \\
\end{array}$ \\
\hline & PEG HD & $\begin{array}{c}\mathrm{n} \\
\text { Mean } \pm \text { SD } \\
\text { Median (IQR) } \\
\end{array}$ & $\begin{array}{c}7 \\
0.1 \pm 0.2 \\
0(0,0) \\
\end{array}$ & $\begin{array}{c}6 \\
0.8 \pm 1.0 \\
0.4(0,1.7) \\
\end{array}$ & $\begin{array}{c}5 \\
3.5 \pm 5.1 \\
1.1(0.3,3.7) \\
\end{array}$ & $\begin{array}{c}5 \\
4.2 \pm 3.4 \\
3.7(2.1,5.7) \\
\end{array}$ \\
\hline & BG & $\begin{array}{c}\mathrm{n} \\
\text { Mean } \pm \mathrm{SD} \\
\text { Median (IQR) }\end{array}$ & $\begin{array}{c}6 \\
0.1 \pm 0.3 \\
0.0(0.0,0.0) \\
\end{array}$ & $\begin{array}{c}6 \\
0.2 \pm 0.3 \\
0.0(0.0,0.6) \\
\end{array}$ & $\begin{array}{c}6 \\
0.1 \pm 0.1 \\
0.0(0.0,0.3) \\
\end{array}$ & $\begin{array}{c}4 \\
0.2 \pm 0.3 \\
0.1(0.0,0.4) \\
\end{array}$ \\
\hline & PEG LD/RGD & $\begin{array}{c}\mathrm{n} \\
\text { Mean } \pm \text { SD } \\
\text { Median (IQR) }\end{array}$ & $\begin{array}{c}6 \\
0.1 \pm 0.2 \\
0.0(0.0,0.0)\end{array}$ & $\begin{array}{c}5 \\
0.5 \pm 1.0 \\
0.0(0.0,0.1)\end{array}$ & $\begin{array}{c}6 \\
0.1 \pm 0.2 \\
0.0(0.0,0.0)\end{array}$ & $\begin{array}{c}5 \\
0.5 \pm 0.9 \\
0.0(0.0,0.3)\end{array}$ \\
\hline & PEG MD & $\begin{array}{c}\mathrm{n} \\
\text { Mean } \pm \mathrm{SD} \\
\text { Median (IQR) }\end{array}$ & $\begin{array}{c}7 \\
0.6 \pm 0.7 \\
0.0(0.0,1.1) \\
\end{array}$ & $\begin{array}{c}6 \\
0.2 \pm 0.5 \\
0.0(0.0,0.0) \\
\end{array}$ & $\begin{array}{c}6 \\
0.2 \pm 0.6 \\
0.0(0.0,0.0) \\
\end{array}$ & $\begin{array}{c}4 \\
0.1 \pm 0.1 \\
0.0(0.0,0.1) \\
\end{array}$ \\
\hline & PEG MD/RGD & $\begin{array}{c}\mathrm{n} \\
\text { Mean } \pm \mathrm{SD} \\
\text { Median (IQR) }\end{array}$ & $\begin{array}{c}5 \\
0.2 \pm 0.3 \\
0.0(0.0,0.6) \\
\end{array}$ & $\begin{array}{c}7 \\
0.0 \pm 0.1 \\
0.0(0.0,0.0) \\
\end{array}$ & $\begin{array}{c}7 \\
0.2 \pm 0.2 \\
0.0(0.0,0.4) \\
\end{array}$ & $\begin{array}{c}5 \\
0.4 \pm 0.6 \\
0.0(0.0,0.4) \\
\end{array}$ \\
\hline & $\begin{array}{l}\text { PEG } \\
\text { MD/RGD_LV }\end{array}$ & $\begin{array}{c}n \\
\text { Mean } \pm \text { SD } \\
\text { Median (IQR) }\end{array}$ & $\begin{array}{c}7 \\
0.0 \pm 0 \\
0.0(0.0,0.0)\end{array}$ & $\begin{array}{c}6 \\
0.3 \pm 0.3 \\
0.1(0.0,0.6)\end{array}$ & $\begin{array}{c}5 \\
0.1 \pm 0.3 \\
0.0(0.0,0.0)\end{array}$ & $\begin{array}{c}6 \\
0.0 \pm 0.1 \\
0.0(0.0,0.0)\end{array}$ \\
\hline & PEG HD & $\begin{array}{c}\mathrm{n} \\
\text { Mean } \pm \text { SD } \\
\text { Median (IQR) }\end{array}$ & $\begin{array}{c}7 \\
0.4 \pm 1.1 \\
0.0(0.0,0.0)\end{array}$ & $\begin{array}{c}6 \\
0.3 \pm 0.5 \\
0.0(0.0,0.4)\end{array}$ & $\begin{array}{c}5 \\
1.1 \pm 2.1 \\
0.30 .0,0.6)\end{array}$ & $\begin{array}{c}5 \\
0.2 \pm 0.5 \\
0.0(0.0,0.0) \\
\end{array}$ \\
\hline \multirow[t]{6}{*}{ Background } & BG & $\begin{array}{c}\mathrm{n} \\
\text { Mean } \pm \mathrm{SD} \\
\text { Median (IQR) }\end{array}$ & $\begin{array}{c}6 \\
28.3 \pm 25.9 \\
29.8(4.0,50.3) \\
\end{array}$ & $\begin{array}{c}6 \\
17.5 \pm 20.8 \\
9.9(0.0,42.0) \\
\end{array}$ & $\begin{array}{c}6 \\
48.2 \pm 16.0 \\
49.0(34.1,50.0)\end{array}$ & $\begin{array}{c}4 \\
65.9 \pm 9.4 \\
67.3(58.2,73.6) \\
\end{array}$ \\
\hline & PEG LD/RGD & $\begin{array}{c}\mathrm{n} \\
\text { Mean } \pm \mathrm{SD} \\
\text { Median (IQR) }\end{array}$ & $\begin{array}{c}6 \\
32.1 \pm 32.3 \\
29.5(0.0,60.8) \\
\end{array}$ & $\begin{array}{c}5 \\
15.1 \pm 13.3 \\
13.6(5.1,15.9) \\
\end{array}$ & $\begin{array}{c}6 \\
42.1 \pm 33.0 \\
47.5(5.9,75.0) \\
\end{array}$ & $\begin{array}{c}5 \\
63.4 \pm 5.7 \\
62.8(61.9,68.2) \\
\end{array}$ \\
\hline & PEG MD & $\begin{array}{c}\mathrm{n} \\
\text { Mean } \pm \text { SD } \\
\text { Median (IQR) }\end{array}$ & $\begin{array}{c}7 \\
16.4 \pm 19.2 \\
13.1(4.5,17.0) \\
\end{array}$ & $\begin{array}{c}6 \\
31.3 \pm 26.2 \\
34.1(1.7,55.7)\end{array}$ & $\begin{array}{c}6 \\
37.0 \pm 22.2 \\
41.2(27.0,55.4) \\
\end{array}$ & $\begin{array}{c}4 \\
50.9 \pm 28.0 \\
54.3(32.2,69.5) \\
\end{array}$ \\
\hline & PEG MD/RGD & $\begin{array}{c}\mathrm{n} \\
\text { Mean } \pm \mathrm{SD} \\
\text { Median (IQR) }\end{array}$ & $\begin{array}{c}5 \\
17.1 \pm 13.8 \\
15.3(8.9,19.3)\end{array}$ & $\begin{array}{c}7 \\
13.5 \pm 9.4 \\
12.5(6.3,18.8)\end{array}$ & $\begin{array}{c}7 \\
55.9 \pm 25.7 \\
62.5(51.1,68.8)\end{array}$ & $\begin{array}{c}5 \\
55.5 \pm 25.1 \\
58.0(49.9,74.8)\end{array}$ \\
\hline & $\begin{array}{l}\text { PEG } \\
\text { MD/RGD_LV }\end{array}$ & $\begin{array}{c}n \\
\text { Mean } \pm \text { SD } \\
\text { Median (IQR) }\end{array}$ & $\begin{array}{c}7 \\
25.6 \pm 21.9 \\
23.01(0.0,39.2)\end{array}$ & $\begin{array}{c}6 \\
11.0 \pm 19.9 \\
3.0(0.0,9.1)\end{array}$ & $\begin{array}{c}5 \\
26.7 \pm 26.5 \\
10.8(7.7,53.1)\end{array}$ & $\begin{array}{c}6 \\
53.6 \pm 15.3 \\
54.8(48.3,60.2)\end{array}$ \\
\hline & PEG HD & $\begin{array}{c}n \\
\text { Mean } \pm \text { SD } \\
\text { Median (IQR) }\end{array}$ & $\begin{array}{c}7 \\
20.1 \pm 14.4 \\
26.1(4.5,31.3) \\
\end{array}$ & $\begin{array}{c}6 \\
18.4 \pm 18.3 \\
15.3(2.3,35.2)\end{array}$ & $\begin{array}{c}5 \\
3.9 \pm 4.3 \\
3.1(0.6,4.8) \\
\end{array}$ & $\begin{array}{c}5 \\
24.8 \pm 16.3 \\
30.5(9.1,30.7)\end{array}$ \\
\hline
\end{tabular}

SD = standard deviation; IRQ = interquartile range; PEG HD = a dense network PEG hydrogel; PEG MD = a medium-dense network PEG hydrogel; PEG $\mathrm{MD} / \mathrm{RGD}=$ a medium-dense network PEG hydrogel modified with RGD; PEG MD/RGD LV = a medium-dense network PEG hydrogel modified with RGD without addition of CMC and according low viscosity; PEG LD/RGD = a loose network PEG hydrogel modified with RGD; BG = a collagen membrane 


\section{Appendix 1}

Statistical analysis:

All measured outcomes were summarized as means and standard deviations, and as medians and interquartile ranges. Comparisons between treatment modalities were first examined pairwise using the Wilcoxon signed rank test (results not shown). To account for the effect of factors such as animal, position of the defect on the skull and side on the respective comparisons of the treatments, mixed linear models were carried out for each time point. The factor animal was added to the model as a random effect, position and side as fixed effects. The mixed linear models were performed using the nonparametric Brunner-Langer method (Brunner \& Langer 1999). Global comparisons (Brunner-Langer, F1_LD_F1 model) of the effects of treatment and time points on each of the outcomes were examined first and then the calculated effects resulting from the above models were adjusted for multiple comparisons using Dunnett-Hsu's correction (Brunner 2010). The calculated effects (the least square means and $95 \% \mathrm{CI}$ of the ranked outcome for each of the levels of the categorical variables were extracted and back transformed to the scale of the original outcome variable) are expressed as adjusted 'means' in the results. The level of significance was set at $p<0.05$. SAS release 9.4 (SAS Institute Inc, 2002-2012, Cary, NC, USA) was used for the statistical analysis.

Brunner, E. (2010) SAS standard procedures for the analysis of non-parametric data. (in German). http://saswiki.org/images/e/e3/5.KSFE-2001-brunner-Einsatz-von-SAS-Modulenf\%C3\%BCr-die-nichtparametrische-Auswertung-von-longitudinalen-Daten.pdf.

Brunner, E. \& Langer, F. (1999) Non-parametric analysis of longitudinal data. (in German). Oldenburgverlag, Munich. 


\section{Appendix 2}

Overall $^{\S}$ effect of treatment, time and interaction between time and treatment.

\begin{tabular}{llc}
\hline Outcome & Parameter & p-Value* \\
\hline Connective tissue (\%) & Treatment & 0.623 \\
& Time point & 0.005 \\
& Treatment * Time point & 0.952 \\
\cline { 2 - 3 } Matrix/Membrane (\%) & Treatment & $<0.001$ \\
& Time point & $<0.001$ \\
New bone (\%) & Treatment * Time point & 0.033 \\
\cline { 2 - 3 } & Treatment & 0.016 \\
& Time point & $<0.001$ \\
Old bone (\%) & Treatment * Time point & 0.872 \\
\cline { 2 - 3 } & Treatment & 0.940 \\
& Time point & 0.914 \\
& Treatment * Time point & 0.742 \\
\cline { 2 - 3 } & Treatment & 0.005 \\
& Time point & $<0.0001$ \\
& Treatment * Time point & 0.146 \\
\hline
\end{tabular}

* Type 3 tests of fixed effects (treatment and time). The effect of an animal was introduced in the model as random effect,

$\S$ Global comparisons done using Brunner-Langer, F1_LD_F1 model 


\section{Appendix 3}

(a)
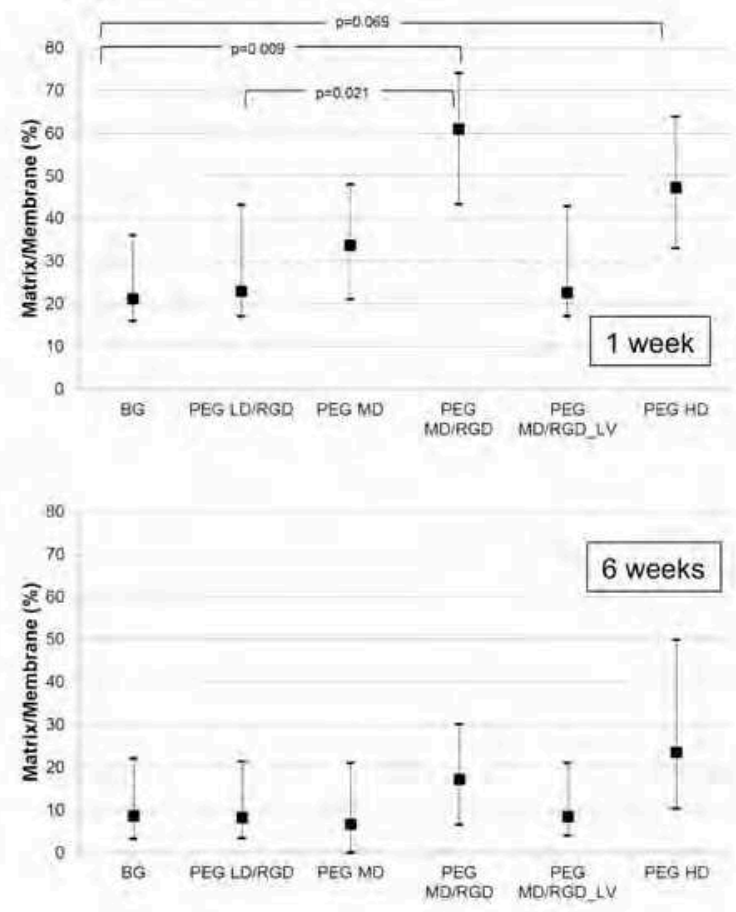

(b)
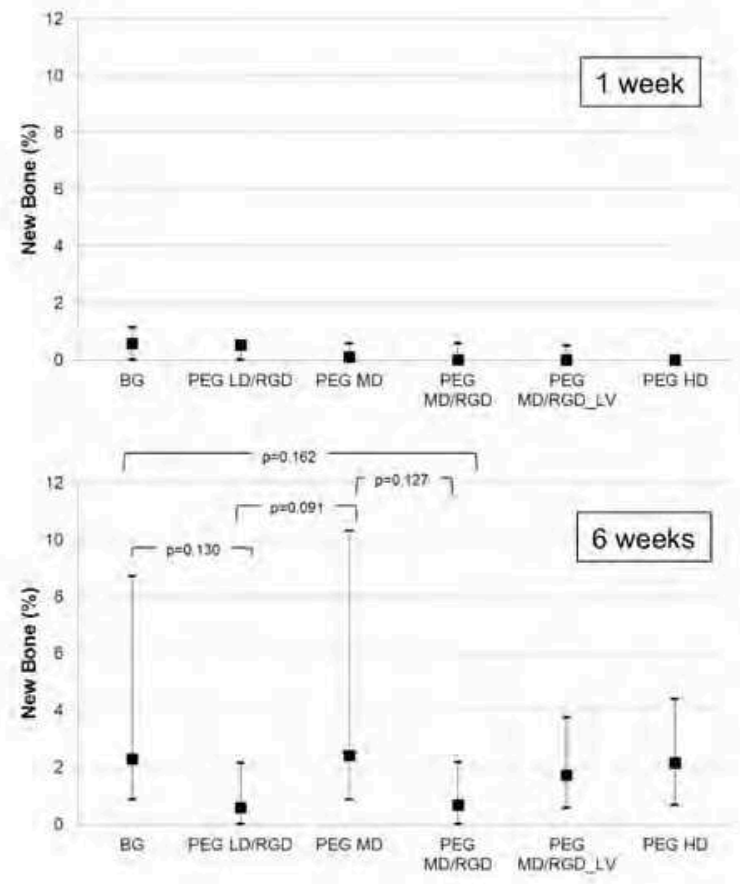

\section{Appendix 4}

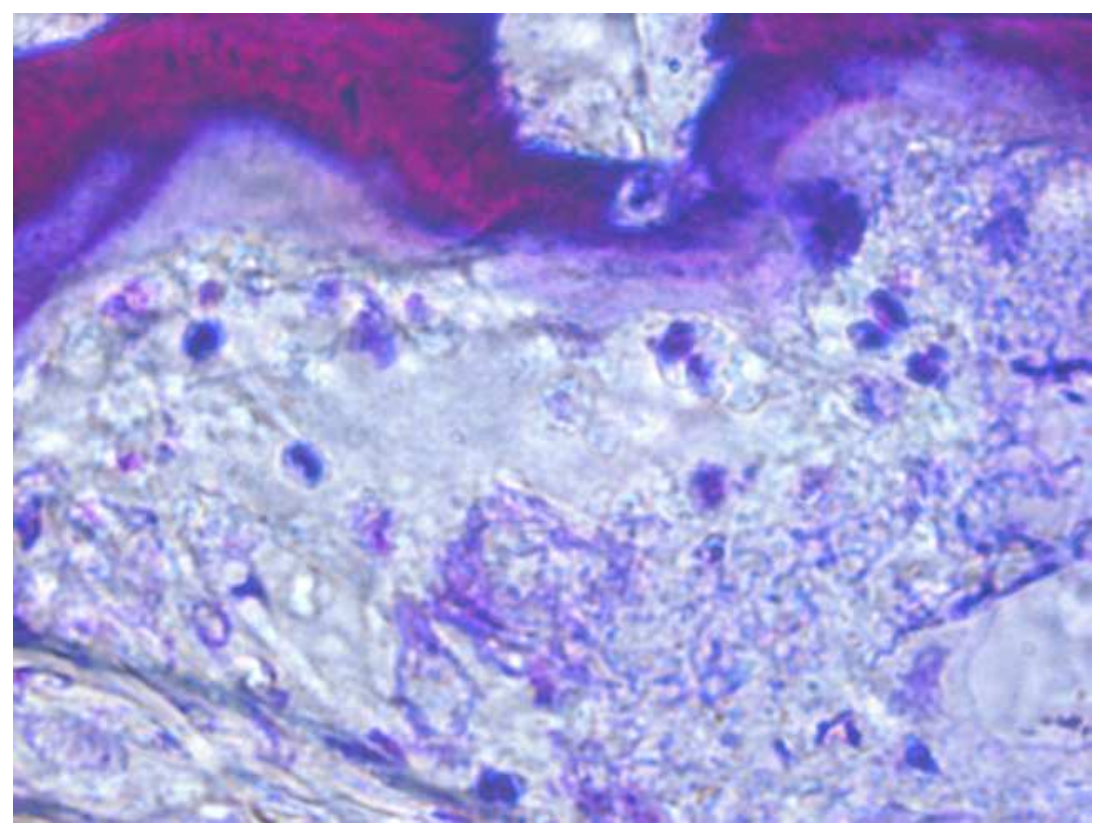




\section{Appendix 5}

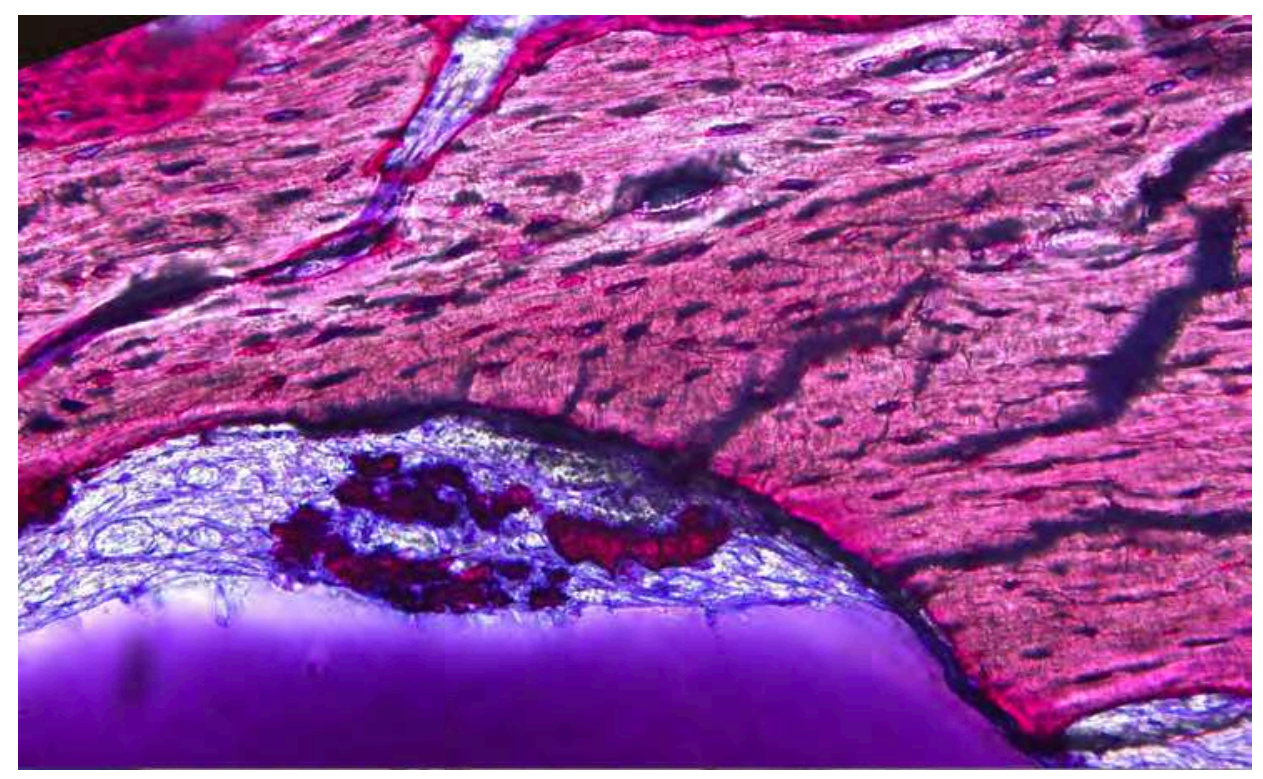

\section{Appendix 6}

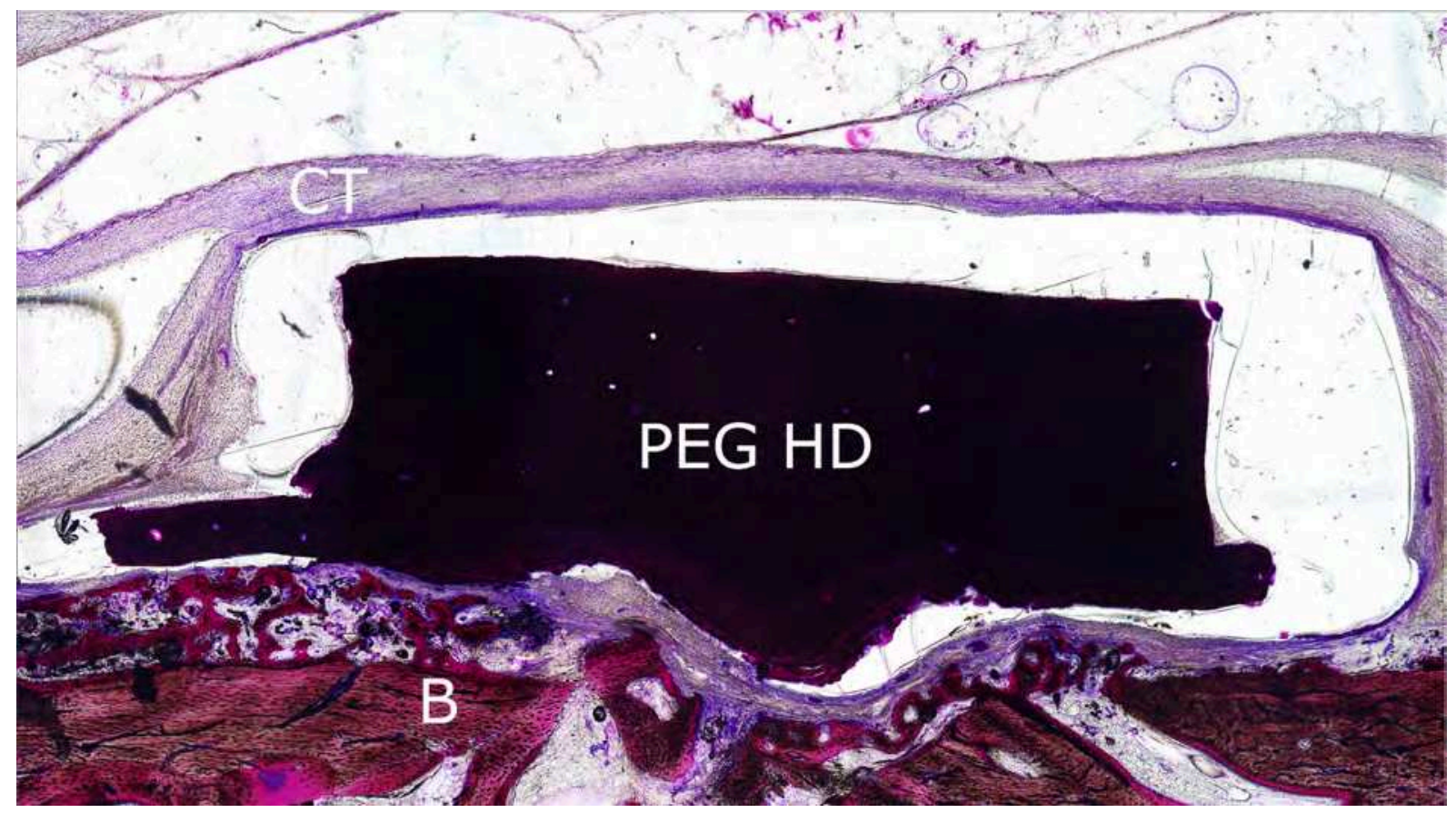




\section{Appendix 7}

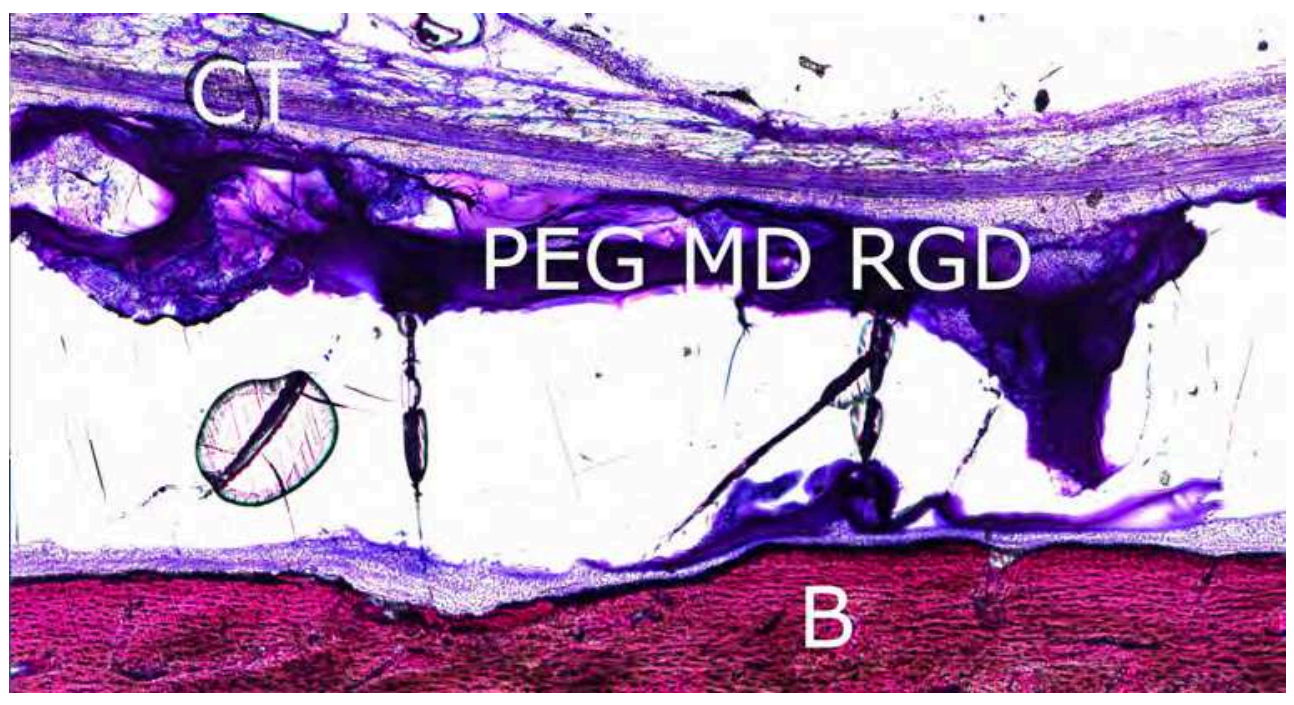

\section{Appendix 8}

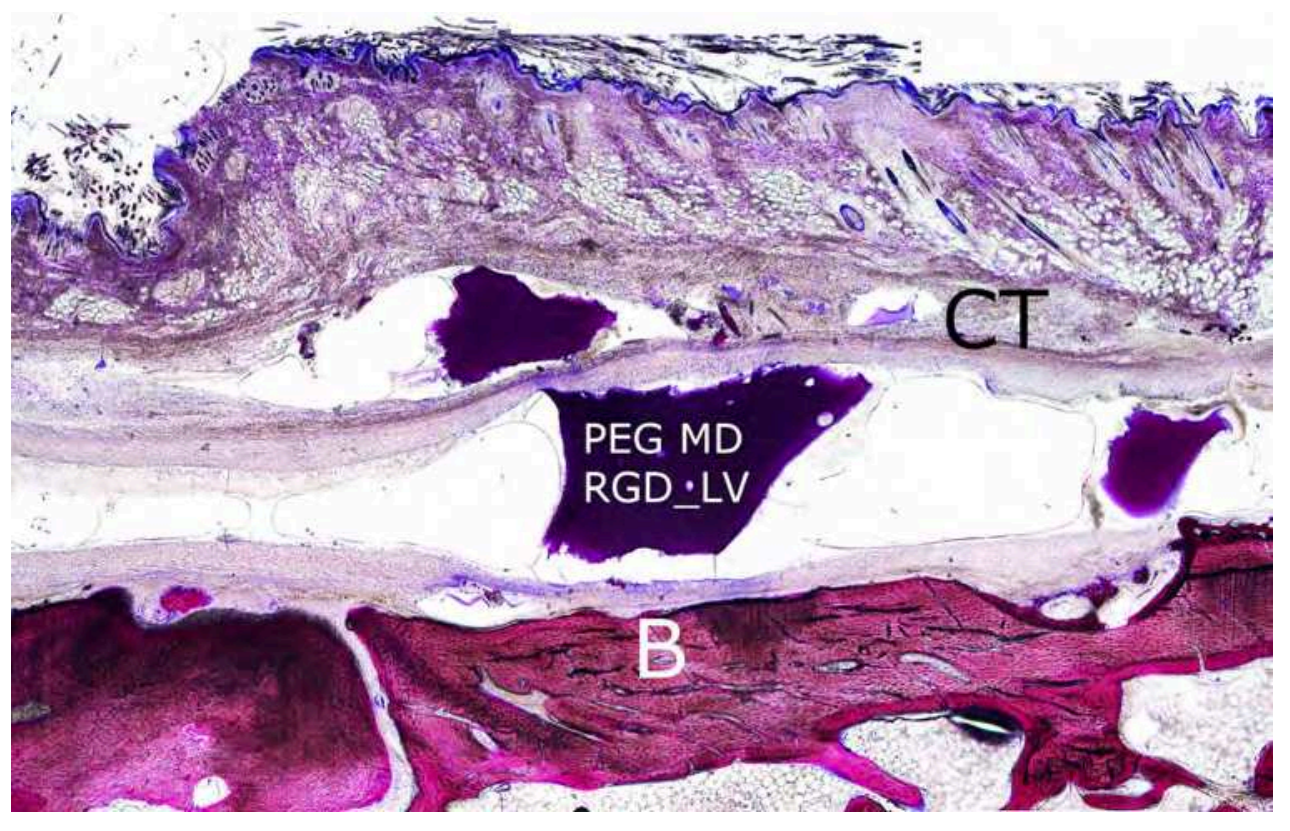




\section{Appendix 9}

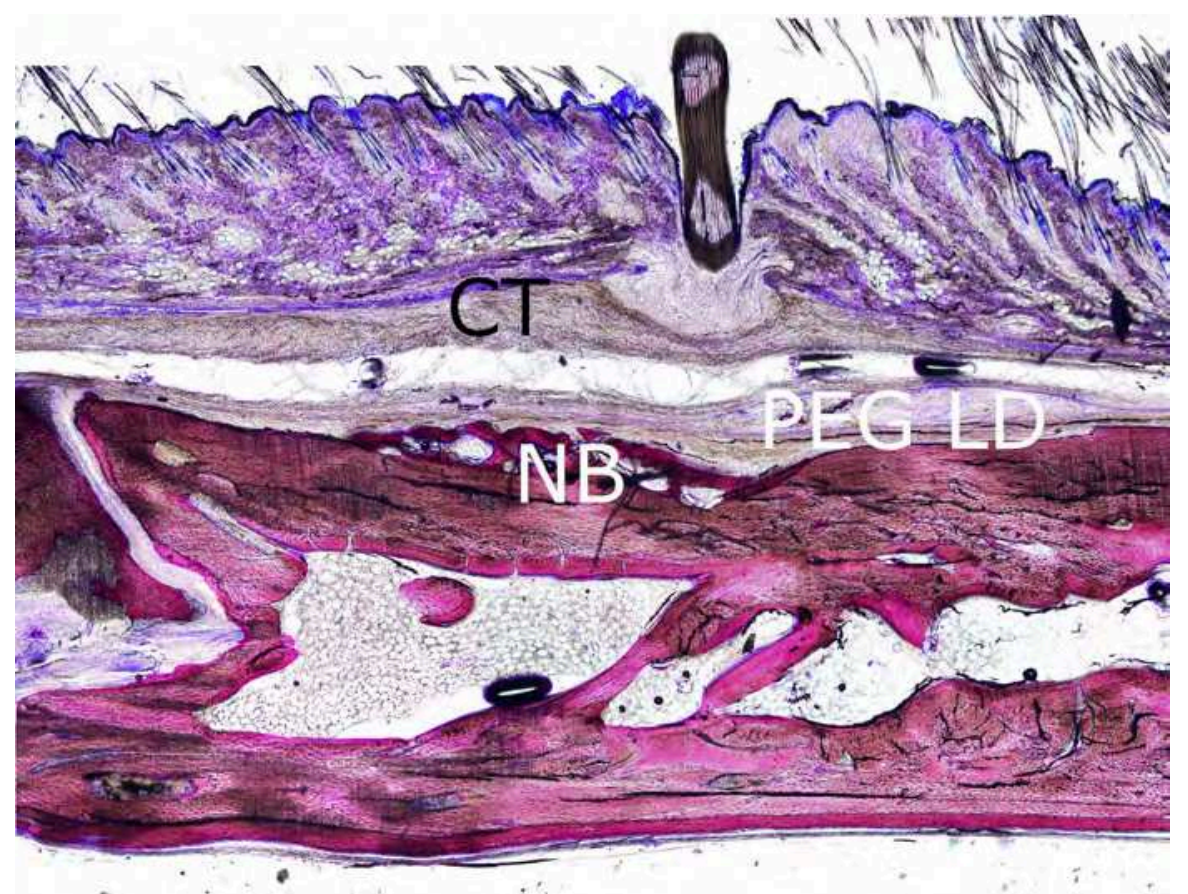

\section{Appendix 10}

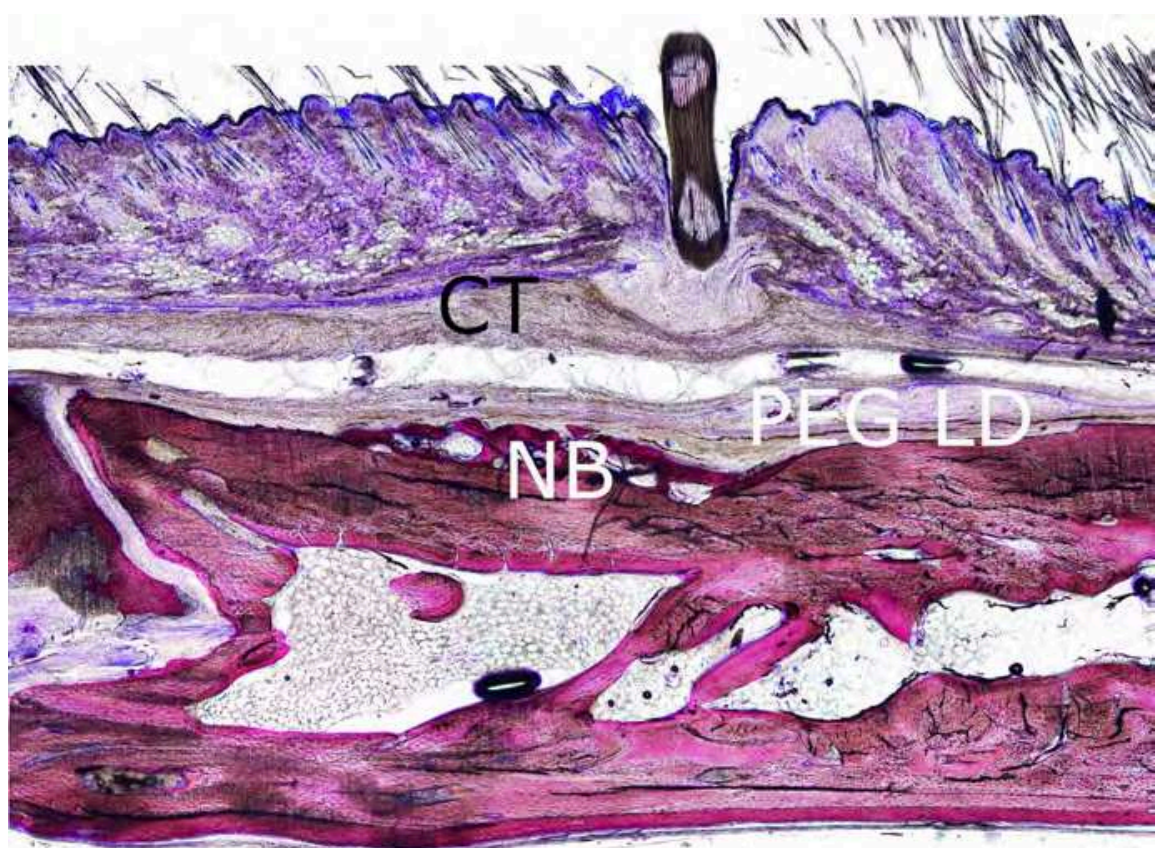

